\title{
Editorial: Intersections and Connections in Open/Technology, Education, Society, and Scholarship
}

Valerie Irvine

Faculty of Education

University of Victoria

Michele Jacobsen

Werklund School of Education

University of Calgary

Colin Madland

Faculty of Education

University of Victoria

Anne-Marie Scott

Athabasca University
Correspondence:

c/o OTESSA Journal

Email: publications at otessa.org

Keywords: educational technology, online learning, open education, digital learning, digital scholarship, digital pedagogy, open scholarship, scholarship, editorial 


\section{Introduction to Proceedings}

We are pleased to share the first collection of conference proceedings from the Open/Technology in Education, Society, and Scholarship Association (OTESSA). This publication is unique in that it combines proceedings from 2020 and 2021 and includes research papers and practice papers. The inaugural international OTESSA conference was planned for Spring 2020 as part of the Canadian Congress of the Humanities and the Social Sciences, to be held at Western University in London, Ontario. The theme for this first gathering was Intersections: Connecting Open/Technology, Education, Society, and Scholarship. Researchers and practitioners were invited to consider the contemporary social, political, economic and information ecosystems that are dramatically shaping our citizenry and our classrooms. OTESSA encouraged presenters to explore the intersection of perspectives and to engage with the complexities that technology and open practice raise for education, society, and scholarship, and direct their conference contributions to the core issues of Ethics, Access, and Futures. Along with planning three keynotes on OpenEd, EdTech, and Society, the co-chairs, Valerie Irvine, University of Victoria, and Colin Madland, University of Victoria, planned an outstanding conference program for 2020 that included almost 100 accepted presentations. Regrettably, like the other scholarly associations in Congress, OTESSA had to cancel the Spring 2020 conference due to the sudden onset of the pandemic. However, as a brand new association, we are delighted that most of the presenters from the planned 2020 conference opted to carry their sessions forward to OTESSA's 2021 conference.

In 2021, OTESSA's inaugural conference was held fully online from May 31-June 3, as part of the Canadian Congress of the Humanities and the Social Sciences and in collaboration with the University of Alberta. As one of newest associations at Congress, OTESSA again welcomed researchers, educators, graduate students, designers, librarians, thinkers, and tinkerers from across disciplines and contexts who are exploring the role of open and/or digital technologies in education, society, and scholarship to engage and connect at the 2021 conference. For the program, OTESSA invited a particular focus on the complexities that technology or open education practice raise for education, society, and scholarship and matters of relation. Three sub-themes invited and organized conference submissions and were used to prepare the final program: 1) Online learning and teaching, 2) Inclusive networks and ethical spaces, and 3) Knowledge Engagement and Relationality. Co-Chaired by Michele Jacobsen, University of Calgary, and Anne Marie Scott, Athabasca University, OTESSA's 2021 Conference attracted more than 55 presentations by researchers and practitioners from across disciplines. Our association's primary focus in 2021 was on building connected and lively conversations and open sharing of scholarship and practice in Open/Technology, Education, Scholarship and Society. Three keynotes provided an inspirational start to each day of the conference: 1) Pandemic Reflections on the OTESSA Conference Themes, by Bonnie Stewart, University of Windsor, George Veletsianos, Royal Roads University, and President of OTESSA, Valerie Irvine, University of Victoria, 2) Supporting Student Engagement in a Connected North, by Michael Furdyk, Connected North, and 3) Pandemic Paupers and Princes, by Laura Czerniwicz, University of Cape Town.

The editors are profoundly grateful for the patience and fortitude displayed by the OTESSA community in genuinely unprecedented times, especially for those who were at the forefront of the sector-wide pivot to emergency remote teaching at the onset of the pandemic. 
The editors are also hopeful that the work represented here will be fruitful for researchers and practitioners working in educational technology, online learning, open education, or digital/open scholarship around the world. The OTESSA community is uniquely positioned to influence research and practice and we look forward to expanding these annual proceedings in the years to come as we build and grow together. 